Article

\title{
Enhancement of Albedo for Solar Energy Gain with Particular Emphasis on Overcast Skies
}

\author{
Mehreen Gul ${ }^{1, *}$, Yash Kotak ${ }^{2}$, Tariq Muneer ${ }^{3}$ and Stoyanka Ivanova ${ }^{4}$ (D) \\ 1 Centre of Excellence in Sustainable Building Design, Heriot-Watt University, Edinburgh Eh14 4AS, UK \\ 2 Project Management Centre of Excellence, Blackpool and The Fylde College, Blackpool FY2 0HB, UK; \\ yash.kotak@blackpool.ac.uk \\ 3 School of Engineering and the Built Environment, Edinburgh Napier University, Edinburgh EH10 5DT, UK; \\ t.muneer@napier.ac.uk \\ 4 Department Computer-Aided Engineering, University of Architecture, Civil Engineering and Geodesy, \\ Hr. Smirnenski 1, 1164 Sofia, Bulgaria; solaria@mail.bg \\ * Correspondence: m.gul@hw.ac.uk; Tel.: +44-131-451-4082
}

Received: 8 October 2018; Accepted: 23 October 2018; Published: 24 October 2018

check for

\begin{abstract}
In the absence of ground reflected radiation measured data, an average albedo value of 0.2 , which describes the reflective properties of the bare ground is generally used. The variation of albedo based on different foreground surfaces and under different atmospheric conditions is an area which is under research. This paper presents an experimental investigation of albedos of different foreground materials that can be used for photovoltaic (PV) applications. Overcast skies are predominant in northerly locations and will have a high frequency of low solar altitudes, and thus ground reflection is an important contributor towards total solar energy gain. The foreground surfaces include common materials: Grass, sand, and cement slabs, and some non-conventional materials: White pebbles, white boards, white tiles, and aluminium foil. The impact of factors, such as ageing, solar elevation, rain, and cloud cover (sky conditions) is analysed to determine the changes in albedos of these materials. Each material was observed to have individual performance characteristics under these factors. It was found that the non-conventional materials were least prone to weather-related changes and have higher albedo values as compared to the conventional materials, and also have good potential to replace the conventional materials for any given PV application.
\end{abstract}

Keywords: solar radiation; photovoltaic; albedo; overcast skies

\section{Introduction}

The optimal design of a solar photovoltaic (PV) system relies upon accurate performance predictions of electrical and environmental factors that affect the performance of the system [1]. A PV plant goes through two key stages, development and forecasting the power output [2], with various kinds of information on the solar resource needed at each stage. In the development stage, reliable solar radiation statistics are required for plant location, system design, and for the feasibility study. In most cases, monthly average values of solar irradiation are sufficient [2]. There are many existing projects and databases available online, as cited by Kotak et al. [3], which provide ample information for the development stage of a PV power plant. In most situations, the data, either raw or completed by estimations, may fulfil the needs of users. Real-time data is critical for optimizing supply and demand patterns in the power grid with multiple fluctuating renewable sources, such as solar, wind, and tidal. Forecasting the power output from these renewable sources is therefore essential for the proper functioning of the grid.

To accurately predict the output of a PV system, it is essential that the solar irradiance calculations are precise (closely match with real-time data). There are three main components of solar radiation on 
an inclined surface: (a) Direct beam; (b) diffuse from the sky; and (c) reflected from the foreground, where the reflected component is generally $10 \%$ of the total incident radiation [4]. There are several stations worldwide that measure horizontal solar radiation, but very few measure solar radiation components on tilted surfaces. The regular practice, therefore, is to develop new or use existing algorithms that calculate the incident solar irradiance on a tilted surface from the horizontal. In the last fifteen years, there have been many models developed worldwide for the evaluation of inclined radiation from the horizontal, for various locations. These include $[5,6]$ and others as cited by Kotak et al. [3]. These models transpose the direct-beam and diffuse radiation components on the horizontal surface to the tilted one; nevertheless, to obtain optimum output from the PV system, they must consider the reflected radiation component from the foreground and surrounding surface.

In general, ground-albedo, or simply 'albedo', is defined as the ratio between the ground-reflected radiation and the global radiation incident on the ground [7]. It is a dimensionless fraction and is measured on a scale from 0 to 1 . An albedo of 0 is of a perfectly black surface (no radiation is reflected, all absorbed), and an albedo of 1 is of a highly reflective material (mirror or white surface) possessing total reflection (no radiation absorption) [8,9]. According to Psiloglou et al. [6], ground reflected albedo is a significant parameter and may reach up to $100 \mathrm{~W} / \mathrm{m}^{2}$. In the absence of ground reflected radiation measured data, a ground albedo value of 0.2 is widely accepted and is used in the modelling of PV systems. Foreground surfaces may have different albedos, and hence a constant albedo value is unsuitable. The albedo value becomes even more significant in the case of bifacial PV cells, which are meant to produce more energy as they collect radiation on the front as well as on the rear side by capturing light reflected from the surface beneath the module and from the surroundings. Moreover, overcast skies are predominant in northerly locations and will have a high frequency of low solar altitudes, and thus ground reflection is an important contributor towards total solar energy gain. This point shall be emphasised furthermore later on in this article.

This paper presents an experimental investigation of albedos of different foreground materials that can be used for enhancing the energy gain of PV applications. A detailed investigation into how the albedo is affected by the factors, such as ageing, solar altitude, rain, and cloud cover (sky condition), was undertaken to suggest the most suitable foreground material that can be used for enhancing the energy gain of PV systems for a northerly location. Overcast skies are predominant in northerly locations and will have a high frequency of low solar altitudes, and thus ground reflection is an important contributor towards total solar energy gain. This point shall be emphasised furthermore later on in this article.

Section 1 provides a succinct review of the factors that are likely to cause variations in the albedo of a given surface. Section 2 details the description of the experiment followed by the methodology for data filtration and analysis. The results are presented in Section 3, and Section 4 discusses each material individually and provides a comparison of all, to infer the most appropriate foreground material for different types of PV applications. Section 5 provides the overall conclusion of this experimental research and also highlights current limitations of the study, and some directions for future research work.

\section{Background}

Many researchers [10-13] have reviewed albedos of a variety of ground surfaces, such as snow, water, forest, deserts, and vegetation, and observed that all ground surfaces have different albedo values. It has been found that forests, lakes, and oceans reflect relatively small fractions of the incident sunlight and have low albedo values while surfaces, like snow and sea ice, reflect large fractions of the incident sunlight and have a higher albedo.

The data presented for 27 US [14] and seven Canadian locations [15] show a very strong seasonal dependence and a variety of albedo values. Similarly, Ineichen et al. [16] measured the actual ground reflected radiation and compared this with the Liu and Jordan value of 0.2 for Geneva, and concluded 
that the constant value of 0.2 is too high and should be abandoned. In addition, Ineichen et al. [8] have also claimed that the constant value is unsatisfactory and unrealistic.

In general terms, the albedo value is a function of solar altitude and degree of cloudiness. For high latitude locations, the measure of albedo under overcast conditions is more important due to a higher proportion of the diffuse component. Table 1 presents the annual diffuse fraction for eight UK locations as provided by the local meteorological office. For most locations, the diffuse ratio exceeds $60 \%$, also confirmed by Photovoltaic Geographic Information System (PVGIS) data, which shows a 63\% diffuse ratio for Edinburgh [17].

Table 1. Annual diffuse ratio for UK locations.

\begin{tabular}{cc}
\hline Location & Annual Ratio of Diffuse to Global Irradiation \\
\hline Jersey & 0.51 \\
Easthampstead & 0.59 \\
London & 0.58 \\
Aberporth & 0.56 \\
Cambridge & 0.60 \\
Aldergrove & 0.61 \\
Eskdalemuir & 0.61 \\
Lerwick & 0.63 \\
\hline
\end{tabular}

Another issue relating to albedo is that it is a weather and time-dependent function. Munn and Truhlar [18] reported albedo values for afternoon periods that were higher than the morning equivalent, but they made no comment regarding this observation. Impens and Lemeur [19] also reported a diurnal variation with marked asymmetry around noon. Bolsenga [20] performed a series of measurements on the ice and demonstrated the influence of solar elevation on albedo. Bray et al. [21] showed that albedo over Quercus forest increased from 3.8\% at a solar elevation of $0^{\circ}$ to $12.3 \%$ at an elevation of $8^{\circ}$ to $10^{\circ}$ and then decreased to $2.4 \%$ at an elevation of $60^{\circ}$ to $70^{\circ}$. The experiment conducted by Volz [22] concluded that the effective albedo of the earth surface is increasing from 0.1 at $40^{\circ}$ solar elevation to about 0.25 at $10^{\circ}$ elevation. This was concluded after taking into consideration materials, such as grass, fir twigs, sand, clay, and soil. Yang [23] stated that the albedo for bare soil depends on soil moisture and soil color types, and does not depend on the solar zenith angle (SZA), whereas the albedo for vegetation depends on vegetation characteristics, such as the leaf and stem area index, and also on the SZA for the solar direct beam. Yang [23] also stated that the albedos for the direct and diffuse beams have different characteristics, where the diffuse-beam albedo does not change with the SZA while the direct-beam albedo does. Usually, the diffuse part increases as the SZA increases and also increases as cloud amount increases.

Idso [24] and Idso and Reginato [25] described the diurnal variation of the albedo of a field of Avondale loam soil and noted three categories of characteristic daily albedo variations. He also showed the correlation between albedo and solar elevation and plotted the graphs of both wet and dry soils. Similarly, Mattias et al. [26] also presented tables of albedo values from two soil types with diverse combinations of wet/dry conditions and roughness, measured at six solar angles (ranging from $20^{\circ}$ to $70^{\circ}$ ) as occurred in generally cloudless days between April and August in 1995 and 1996 at the University of Arizona Campus Agricultural Center in Tucson. The resulted values for dry soil conditions were higher than those for wet soil conditions, at any solar elevation angle.

On average, Earth naturally reflects $8 \%$ of the total solar radiation received from the Sun. Earth's albedo (the Sun's energy reflected into space) has risen in the past few years due to the arctic ice disappearing fast, resulting from deforestation, burning wood, and fossil fuels. As the white surfaces decrease in area, less energy is reflected into space, causing global warming [27]. The variation of albedo values based on different surfaces and under different atmospheric conditions is an area that is under researched. The measurement and detailed analysis of the albedo of a given material is therefore prerequisite to determine the ground reflected irradiance not only on a PV module, but also helps 
scientists understand and predict how various surface features influence both short-term weather patterns as well as longer-term climate trends [28].

\section{Materials and Methods}

To analyse the impact of factors affecting albedo for different foreground materials, an experiment was setup at Heriot-Watt University, Edinburgh, UK. Seven materials were used based on the type of solar PV power generation applications. These included: Grass, sand, cement slabs, white tiles, white pebbles, white painted wooden boards, and aluminium foil. There may be large-scale applications, such as solar farms, mostly cited in agricultural areas and building attached photovoltaics (BAPV), which, as the name suggests, are attached to a building roof or wall. The most common materials used in solar farms are grass and sand, whilst for BAPV applications, cement and shingles or terracotta tiles are widely used [29]. In addition, some non-conventional materials, such as white pebbles, white boards, white tiles, and aluminium foil, were also researched. The reason for choosing these non-conventional materials was the higher reflectivity that they offer, which results in a higher incident irradiation gain.

For the measurement of albedo there are two ASTM (American Society for Testing and Materials) standard testing methods for determining ground reflectance: (a) ASTM E1918 [30]; and (b) dual-pyranometer [31]. In the current research, the dual-pyranometer method was selected as it minimises the measurement error using two pyranometers, one facing upwards towards the sky and another facing downward towards the ground, to record both incoming radiation and reflected radiation at the same time. Each foreground material was laid on a levelled ground of an area of $25 \mathrm{~m}^{2}$ and the ground facing pyranometer was installed at a height of $0.5 \mathrm{~m}$ from the ground. According to Howell et al. [32], this setup ensures maximum radiation exchange (97\%) takes place between the ground and pyranometer when placed at a height of $0.5 \mathrm{~m}$. Both the pyranometers used in this research were of CMP6 series models bought from the Kipp and Zonen Company, which were provided with individual outputs connected to a data logger for recording (see Section 2 for data recording time duration). CMP6 are first class pyranometers, which were fully calibrated, with uncertainties of $\pm 5 \%$ for resolution and spectral sensitivity, and $\pm 2 \%$ for stability and temperature response, where the overall effect contributes only a small percentage error to the measurements [33]. The data acquisition system (data logger) was an SQ2040 4F16 data logger bought from the Grant Data Acquisition Company.

\section{Data Collection and Analysis}

Data collection took place from April to late September of 2016. The data logger was set to record data every $10 \mathrm{~s}$ from the pyranometers. The recorder timings were set based on sunshine hours, i.e., daylight hours, in Edinburgh. The data logger was set to automatic mode, in which it started at 5:00 a.m., recorded data every $10 \mathrm{~s}$, and finally stopped at 10:00 p.m. This automatic recording was kept on for at least two weeks for each material, unless it was necessary to stop for any unforeseen circumstances. In that case, such material was kept for more than two weeks, so that at least 14 days of data was collected for each material. Rain data was collected from an onsite weather station (less than $50 \mathrm{~m}$ away from the experimental site) (Wireless Vantage Pro2 Plus). Visual basic for applications (VBA) code was developed to process and analyse the data. Raw data was converted to a text file to be used as input for the VBA routines.

Stage 1: This stage consists of four steps and are explained as follows:

- Step i: A quality control code was built in the VBA to: (a) Filter out the missing or any incorrect data, i.e., data that have negative values or where the ground reflectivity values were greater than the total global irradiation; (b) average the $10 \mathrm{~s}$ of raw data to one minute; and (c) calculate the albedo of each minute data (Equation (1)):

$$
\rho=\mathrm{R}_{\mathrm{h}} / \mathrm{G}_{\mathrm{h}}
$$


where $\rho$ is the surface albedo, $R_{h}$ is the ground reflected radiation, and $G_{h}$ is the global horizontal radiation [8].

- Step ii: VBA code was built to analyse sky conditions (overcast (OV), part-overcast (POV), and clear $(\mathrm{CL})$ ) of each minute data, obtained from step i. This code computes each minute's solar elevation and the respective clearness index $\left(\mathrm{K}_{\mathrm{T}}\right)$. Note: $\mathrm{K}_{\mathrm{T}}$ is defined as the global solar radiation on the surface of the Earth divided by the extraterrestrial radiation at the top layer of the atmosphere [34].

- Step iii: VBA code was developed to separate the data obtained from step ii into OV, POV, and CL sky conditions. The generated $\mathrm{K}_{\mathrm{T}}$ values in step ii were analysed as: (a) $\leq 0.3$ as $\mathrm{OV}$; (b) $>0.3$ to $\leq 0.7$ as POV; and (c) $>0.7$ as CL sky conditions [13].

- Step iv: VBA code was built to average the data points of the solar elevation and their respective albedo values. Graphs of albedo vs. solar elevation were generated for all materials.

Stage 2: In this stage, an analysis of factors that affect albedo, such as ageing, solar elevation, rain, and sky condition (cloud cover), was carried out. The whole process of data collection and analysis process is clearly shown in Figure 1.

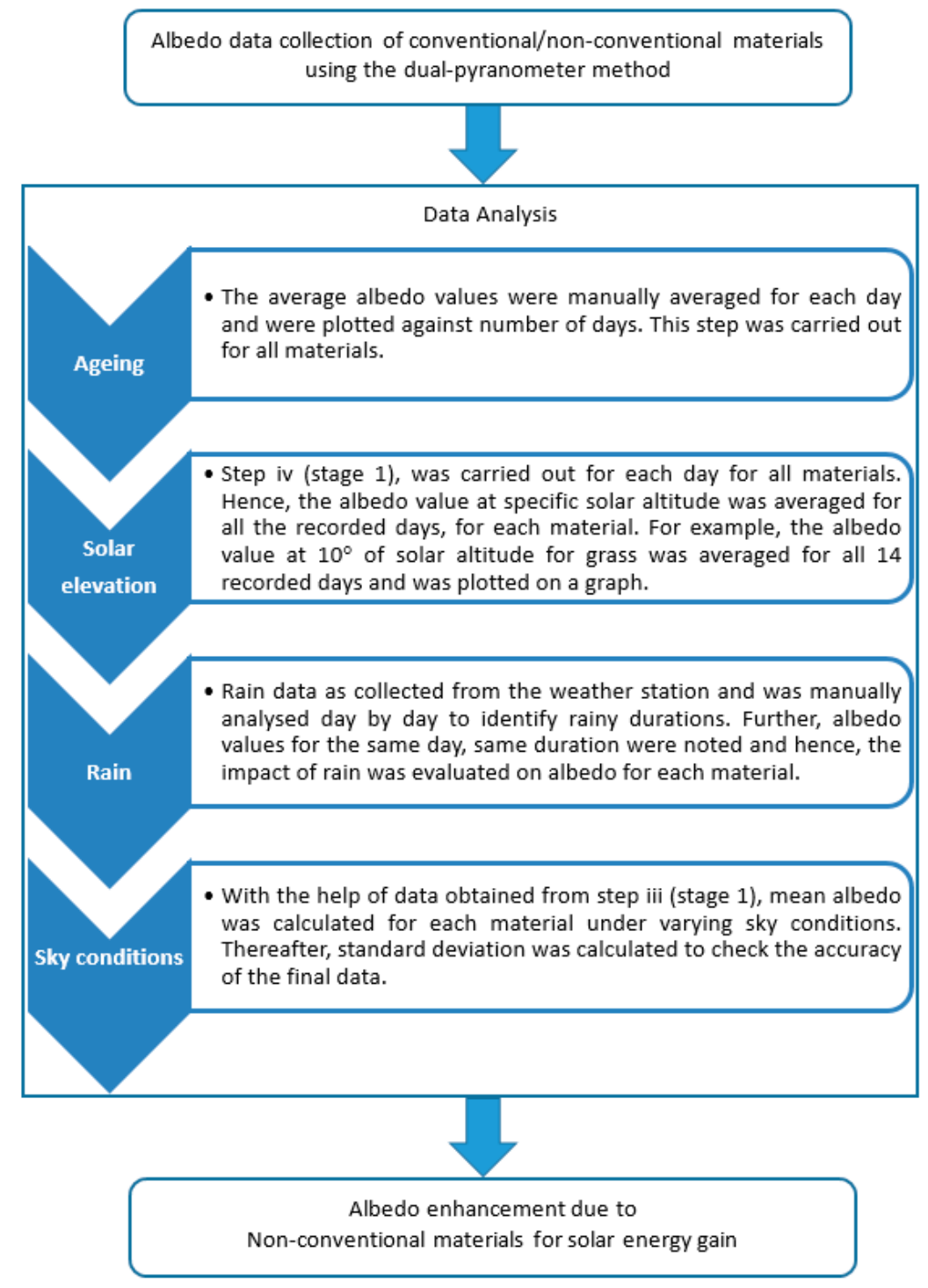

Figure 1. Data collection and analysis sequence. 


\section{Results}

The collected data shows the dominance of overcast skies, which is as expected of Edinburgh's climate. As mentioned in Section 1, overcast skies are the norm at high latitude locations, where the data collected in this programme of work also reflects the proportion of overcast to clear sky data, which was found to be four parts to one. The following sections discuss the impact of four factors: Ageing, solar elevation, rain, and cloud cover for the chosen materials.

\subsection{Ageing}

Figure 2 presents the temporal analysis of the seven materials under investigation. The data was recorded for a maximum of 20 days, and, within these days, a marked ageing difference was noted. For grass, the albedo varies between 0.21 and 0.27 . It was observed that initially when the grass height was small (around seven days), dark bare soil played a major role in lowering the albedo. Within a few days, as the grass started growing, the shiny surfaces of the grass blades enhanced the reflectivity, leading to a higher albedo of 0.27 . As the height of the grass blades increased, they started to bend and caused multiple reflections within the individual blades and soil, which started blocking the sunlight. This diffusion of incident light, therefore, led to a lower albedo value of 0.23 on later days (from the 17 th day onwards).

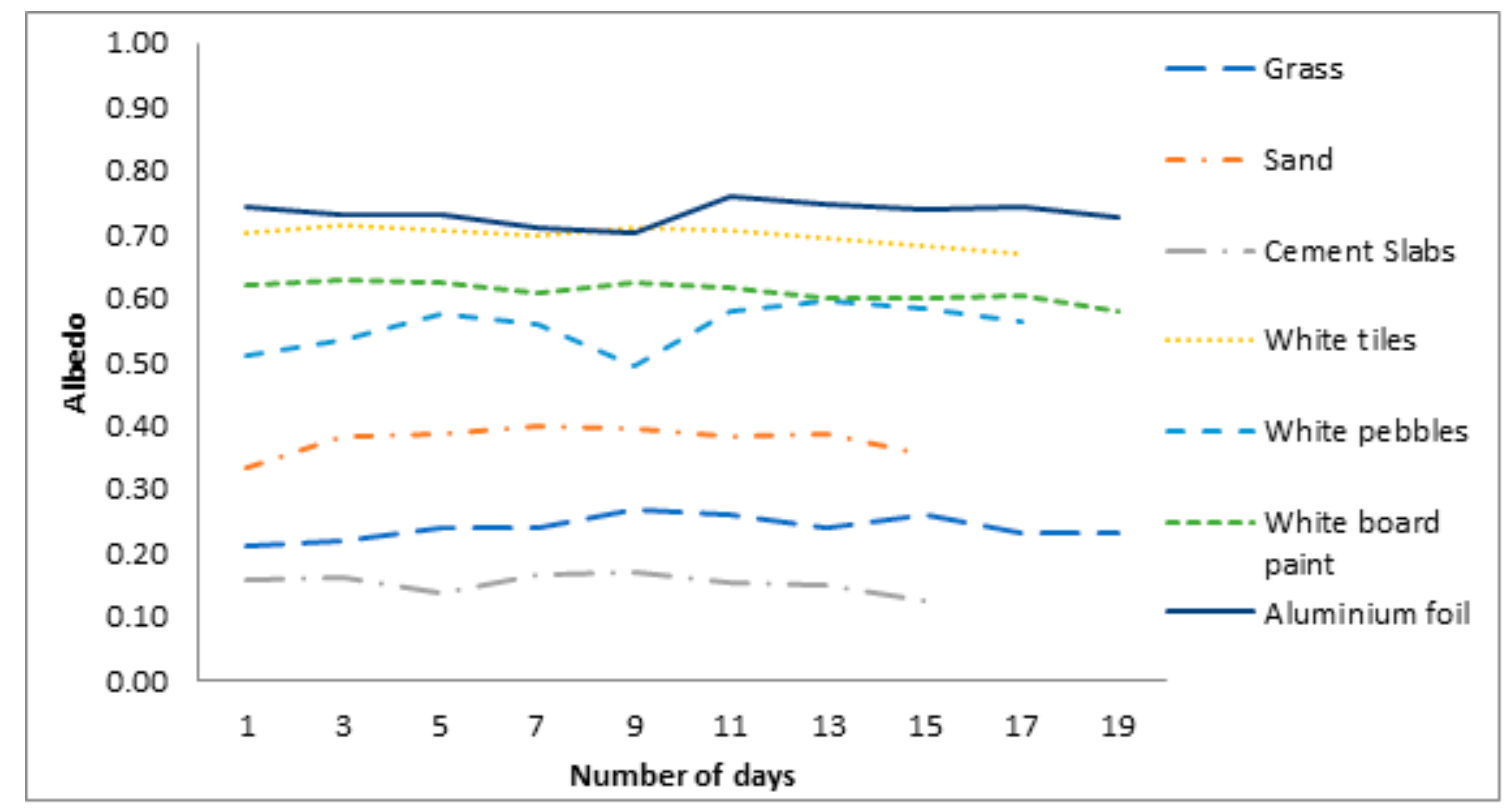

Figure 2. Ageing of materials analysed.

For sand, it was observed that the average albedo value of a complete day remained fairly constant (0.4), with the exception of day 1 and day 15 where the albedo value was found to be 0.34 . This decrease in albedo can be correlated to rain and moisture within the sand. On the first day of measurements, the sand appeared quite wet with a high moisture content, thus causing an increase in its irradiation absorption capacity and lowering the albedo value. Without controlling the moisture content of the soil, a visual inspection carried out by the authors on the second day observed that the sand was almost as dry as one would normally expect, which raised the albedo value to around 0.4.

The albedo value of white pebbles was found to be in the range of 0.5 to 0.6. During data collection, it was noticed that within the first few days (from the 5th day to the 9 th day), the pebble bed was covered with litter from nearby trees dropping limbs, narrow willow-like leaves, and twigs. Due to this cover, there was a drop of $18 \%$ in albedo, as compared to its maximum albedo value $(\rho=0.6)$. After cleaning and placing the white pebbles again, the albedo value returned to its original range, i.e., between 0.5 and 0.6 (from the 10th day to the 17th day) (see Figure 2). 
From Figure 2 it can be seen that the albedo value of cement slabs was in the range of 0.12 to 0.17 . There was no specific trend noticed for the change in albedo for cement slabs from day to day. For example, the albedo value for the initial week was around 0.15 and 0.16 , which increased to 0.17 by the end of the week and then declined to 0.12 by the next week.

It can also be noticed from Figure 2 that the albedo value of the white tiles during the first three days was around 0.72 , and for white board, it was around 0.63 . As the days passed on, the albedo value of the white tiles and white paint declined to 0.67 and 0.58 , respectively. One of the major reasons for such a decline was due to the accumulation of general ambient dirt and dust, and the accumulation of plant leaves.

The last material researched was aluminium foil, which, unlike other materials, had to be stapled to wooden boards. Being very thin and pliable, it formed creases and wavy patterns, which resulted in an albedo range between 0.70 and 0.76 . The performance of foil seemed to be significantly different from other materials, where it was observed that the outdoor lifetime of the aluminium foil used was up to a maximum of 10 days. From Figure 2, it can be seen that the albedo value of the foil at the start of the experiment was 0.74 , which decreased to 0.70 in the first 10 days, as the foil was very thin and got torn away due to heavy winds. Hence, when placing it for the second time, more care was taken to try to place it as straight as possible, which resulted in an increase of the albedo value to 0.76 . However, as the days passed, the foil started showing signs of damage, which lowered the albedo value to 0.73 within the following 10 days.

\subsection{Solar Elevation}

Solar elevation refers to the sun angle relative to the Earth's horizon. It is measured in degrees, and its value varies based on the time of day, year, and the latitude of the Earth [35]. Figure 3 presents the variation of albedo with respect to solar elevation for the seven materials.

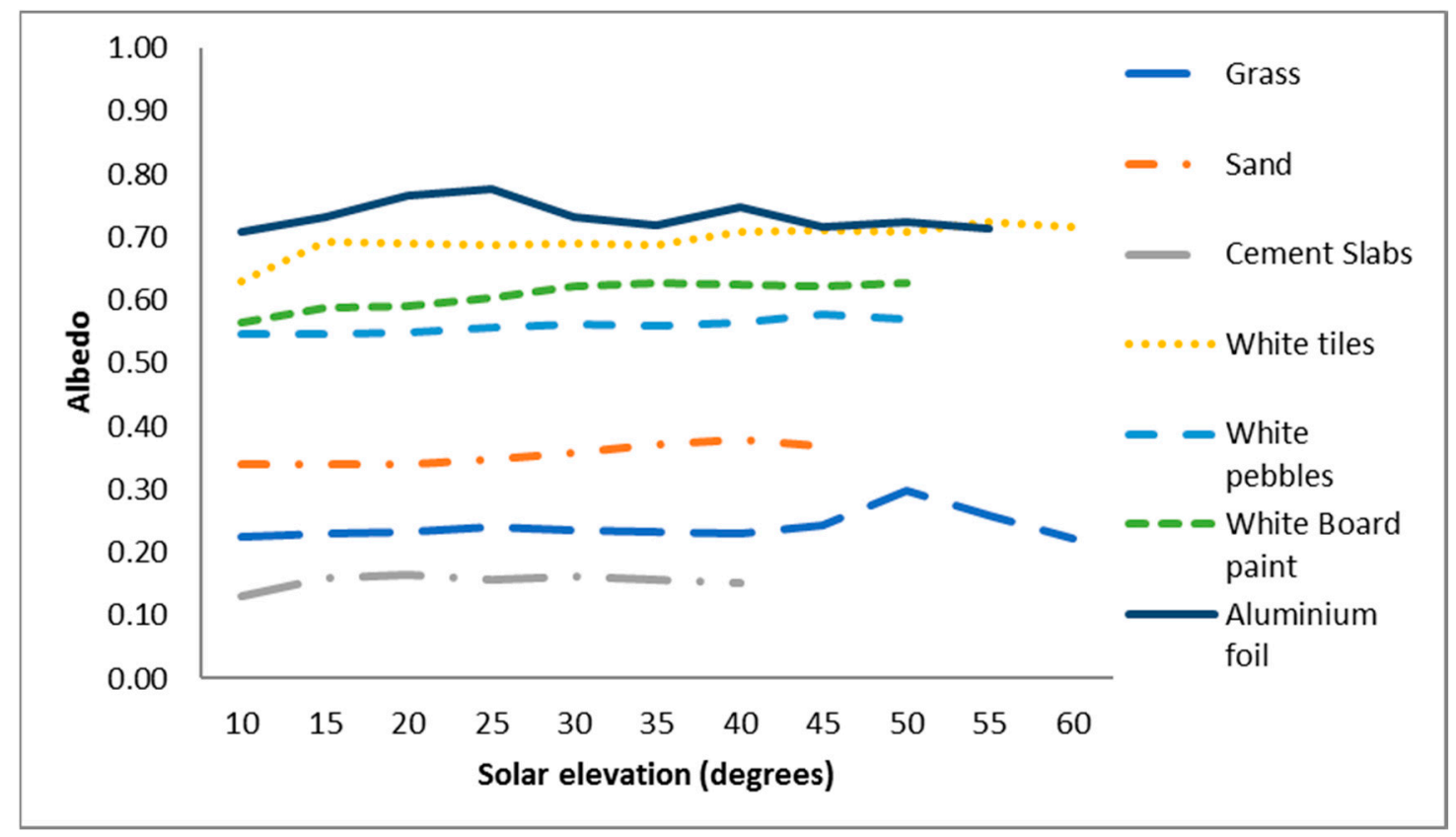

Figure 3. Impact of solar elevation on the researched materials.

It can be noticed that the average albedo values for grass, sand, and cement slabs were $0.24,0.36$, and 0.15 respectively. It can also be seen that the albedo values of each material do not change and remain fairly constant. The only noticeable exception was the grass at $50^{\circ}$ solar elevation. This peak could be attributed to the orientation of the grass blades, i.e., directional reflectance effect, which affects at specific degrees of solar elevation, causing a statistical summation of reflection from the 
multitude of shiny grass blades. The directional reflectance of a surface is defined as the ratio between the radiance reflected and radiance received by the surface.

From Figure 3, it can be noticed that, as the solar elevation increased, the albedo values of white pebbles, boards, and tiles also increased. From $10^{\circ}$ to $50^{\circ}$ of solar elevation, the albedo values of white pebbles and white board paint increased by $2.5 \%$ and $6.3 \%$, respectively. Similarly, for white tiles, the albedo value increased by $8.7 \%$ from $10^{\circ}$ to $60^{\circ}$ of solar elevation. Please note that there were no readings recorded at $60^{\circ}$ of solar elevation for white pebbles and white board paint.

Aluminium foil was the only material that demonstrated a typical behaviour, i.e., no specific trend and/or pattern noticed in terms of albedo varying according to the solar elevation. The albedo values ranged between 0.71 and 0.78 . The only reason that can be concluded for such behaviour was the way the foil was laid out on the ground. The aluminium foil laid on site was curved/wavy in nature, and hence, it is believed that the foil had some mixed reflections (combination of specular and diffuse reflection) at varying solar elevations [36].

In addition, the readers are alerted that the results of many materials demonstrated an increase in albedo with solar elevation (see Figure 3), and this might be due to smaller shadows on the surface from surface features when the Sun is higher in the sky.

Further, in-depth analysis conducted on all materials in terms of the impact of cloud cover (sky condition) revealed that, in general, as the cloud cover decreases, the albedo value increases. An example of this can be seen in Figure 4, where the average albedo value of the white pebbles was plotted against the solar elevation under OV, POV, and CL sky to show the consistently higher values of albedo under clear sky conditions. A similar trend is observed for other materials.

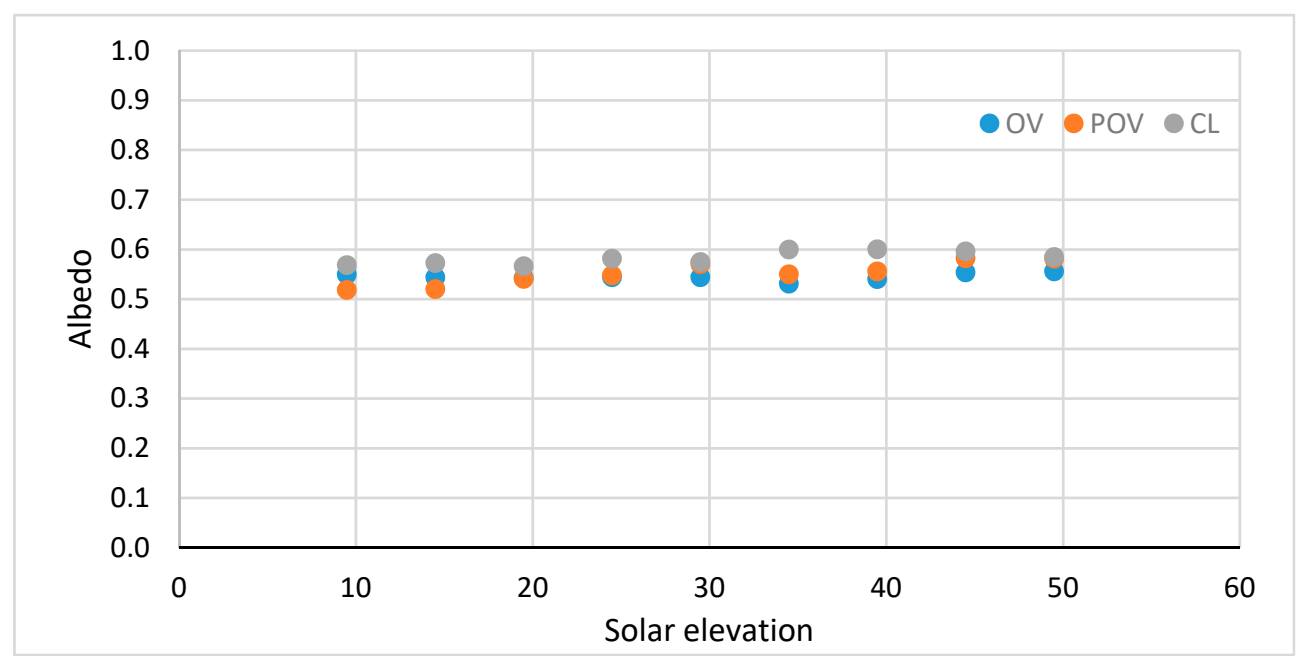

Figure 4. Albedo of white pebbles under varying sky conditions.

\subsection{Rain}

Angstrom [37] observed that after rain, the albedo of light coloured grass decreased from 0.32 to 0.22. During current investigation, it was found that there were three notable days (26th May, 10th and 12th June 2016) with significant rainfall between 6:00 a.m. to 7:00 a.m., 4:00 p.m. to 5:00 p.m., and 9:15 a.m. to 10:15 a.m. The analysis of those days showed that, as the rainfall increased, the albedo value decreased. For example, with 1, 2.2, and $3.4 \mathrm{~mm}$ of rainfall, the measured albedo values were $0.223,0.220$, and 0.218 , respectively. The reason for this decline can be attributed to the water layer (water droplets) on the grass blades acting as a lens (water droplets behave as a concave lens), which can reflect sun rays in different directions, i.e., a ray of light is bent towards the perpendicular axis when entering a higher index medium (like water or glass) and away from the perpendicular axis when exiting it. This effect can be understood by Snell's law of refraction and the concepts of optical physics [22,38]. 
Bowers and Hanks [39] found a very good relationship between the moisture content of sandy loom soil and its reflectivity for various wavelengths. However, no significant information was mentioned in terms of the correlation between albedo and rain. During this current research, there was only one day (2nd September 2016) with $0.4 \mathrm{~mm}$ of rainfall for an hour (8:00 a.m. to 9:00 a.m.) and during that time, the recorded albedo was 0.264 , a decrease of $34 \%$ from the average albedo value. It was also noted that the rainy duration had the OV sky condition, which also contributed towards the declining albedo.

During the experimentation of cement slabs, there were three noticeable days (26th, 27th, and 29th March 2016), which had four to five hours of rainfall during the daytime. The rainy duration on these days lasted from 1:00 p.m. to 6:00 p.m., 11:45 a.m. to 5:45 p.m., and 12:55 p.m. to 3:55 p.m. The average albedo values of this rainy duration were $0.12,0.13$, and 0.15 , respectively.

In the case of the white tiles, there were three days (24th, 25th, and 26th June 2016) with continuous rainfall; the general trend noticed regarding the change in albedo was that, as the solar elevation increased, the albedo value also increased. It was observed that the albedo value during these three days was the same as the albedo value for non-rainy days. This phenomenon of change in the albedo based on the solar elevation can also be noticed in Section 4. For example, there was moderate rainfall throughout the day from the 24th to 26th June 2016 and the average albedo value varied between 0.66 and 0.71 . Typically, on the 24th June 2016, during the rainy time, around $55^{\circ}$ and less than $35^{\circ}$ of solar elevation, the albedo value was 0.71 and 0.69 , which is the same albedo value for non-rainy days as well. Similarly, on the 26th June 2016, the rain duration was between $23^{\circ}$ and $43^{\circ}$ of solar elevation and the albedo value was 0.7 , which also almost matched the non-rainy day's albedo value. However, on the 25th June 2016, the rainy duration was between $23^{\circ}$ and $32^{\circ}$ and the albedo value was 0.66 , which was significantly lower than the usual non-rainy days. This mixed situation of matching and unmatching of albedo values from rainy and non-rainy days can be correlated to the movement of clouds and sky conditions during the daytime. Also, it is possible that the water layer on the white tiles could have been acting as a reflecting lens, causing the incident irradiation to reflect in all directions. Hence, it has been concluded that rainfall does not have a significant influence on the albedo value of white tiles.

There were two days that can be categorised as rainy days during the experimentation on white pebbles. Both days (6th and 12th August 2016) had $0.4 \mathrm{~mm}$ of rainfall for an hour (4:30 p.m. to 5:30.p.m and 4:57 p.m. to 5:57 p.m.), and the albedo value recorded during that hour was 0.48 and 0.5 , respectively. It was interpreted that the albedo value during the rainfall duration was the smallest albedo value recorded (0.5) in terms of any solar elevation or sky conditions.

For white board, it was found that the 27th August 2015 was the only day that could be categorised as a rainy day. It was noticed that throughout the day, there was constant rainfall and hence there was no specific hour that can be accounted for as a rainy duration. The total amount of rainfall recorded was $1.2 \mathrm{~mm}$ and the average albedo value for a complete day was 0.58 .

For aluminium foil, it was found that there were two days that had constant rainfall throughout the day. The recorded rainfall on both the days was $3.6 \mathrm{~mm}$ and $9.2 \mathrm{~mm}$ and the average albedo values were 0.73 and 0.70 , respectively. Therefore, it can be concluded that as the rainfall increases, the albedo value decreases.

\subsection{Cloud Cover (Sky Condition)}

To analyse the effect of cloud cover, three box plots for OV, POV, and CL sky conditions were generated for each material. Herein, the graphs for white pebbles are presented and are shown in Figures 5-7. The analysis of these Figures showed that the albedo variation was significantly low and hence the standard deviation was significantly low from the mean albedo value. Therefore, rather than presenting several graphs for all materials, only one informative table (Table 2) is presented here. 


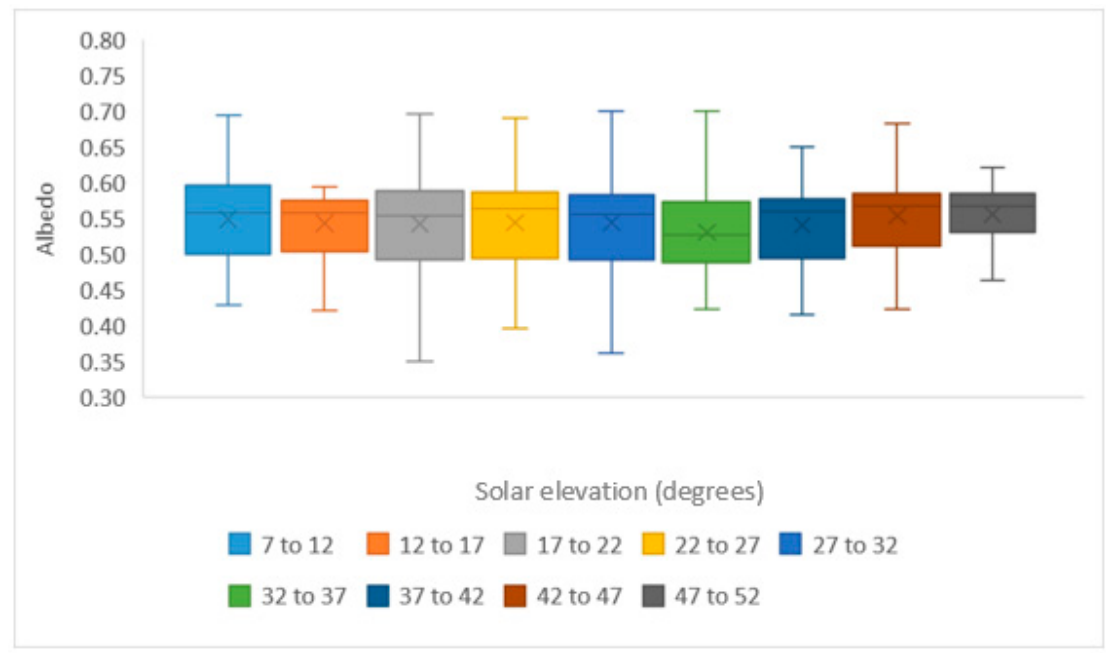

Figure 5. White pebbles' overcast (OV) sky condition for albedo variation against solar elevation. The 11 ranges of solar elevation (degrees) are shown in the legend.

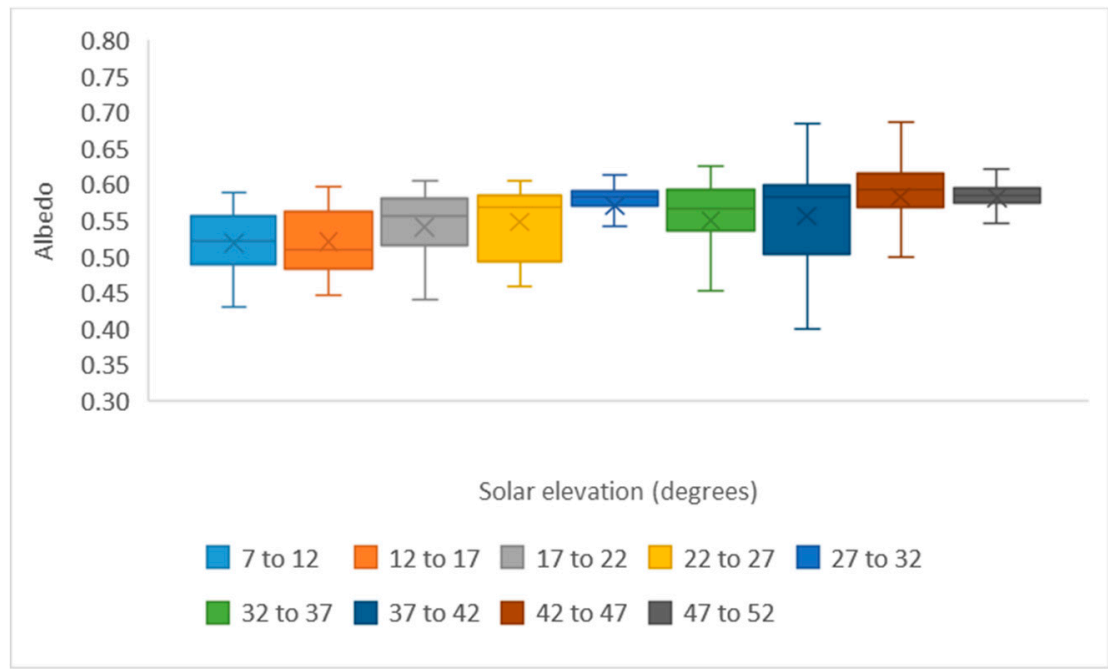

Figure 6. White pebbles' part-overcast' (POV) sky condition for albedo variation against solar elevation. The 10 ranges of solar elevation (degrees) are shown in the legend.

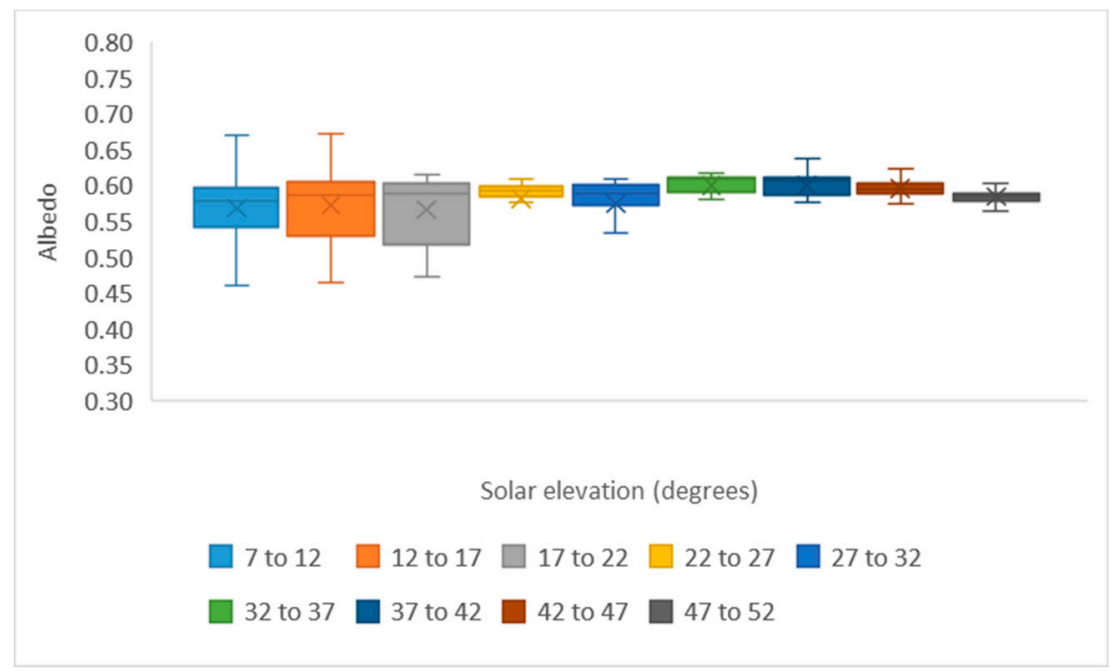

Figure 7. White pebbles' clear (CL) sky condition for albedo variation against solar elevation. The eight ranges of solar elevation (degrees) are shown in the legend. 
Table 2. Data validation of albedo recorded for each material under varying sky conditions.

\begin{tabular}{cccccc}
\hline Surface & $\begin{array}{c}\text { Sky } \\
\text { Condition }\end{array}$ & $\begin{array}{c}\text { Mean of } \\
\text { Albedo }\end{array}$ & $\begin{array}{c}\text { Standard Deviation } \\
\text { of Albedo }\end{array}$ & $\begin{array}{c}\text { Standard Deviation as a } \\
\text { Percent of Mean (\%) }\end{array}$ & $\begin{array}{c}\text { Number of } \\
\text { Data Points }\end{array}$ \\
\hline \multirow{5}{*}{ Grass } & OV & 0.19 & 0.03 & 15 & 4616 \\
& POV & 0.19 & 0.02 & 9 & 3376 \\
& CL & 0.21 & 0.02 & 10 & 4062 \\
\hline \multirow{5}{*}{ Sand } & OV & 0.35 & 0.05 & 14 & 4832 \\
& POV & 0.37 & 0.05 & 14 & 2189 \\
& CL & 0.36 & 0.07 & 19 & 1807 \\
\hline \multirow{3}{*}{ White pebbles } & OV & 0.55 & 0.05 & 9 & 5813 \\
& POV & 0.56 & 0.05 & 10 & 2340 \\
& CL & 0.58 & 0.04 & 6 & 1725 \\
\hline \multirow{5}{*}{ Cement slabs } & OV & 0.13 & 0.04 & 27 & 5825 \\
& POV & 0.16 & 0.03 & 17 & 2695 \\
& CL & 0.17 & 0.04 & 3 & 1817 \\
\hline \multirow{5}{*}{ White tiles } & OV & 0.70 & 0.02 & 3 & 752 \\
& POV & 0.70 & 0.02 & 8 & 650 \\
\hline \multirow{3}{*}{ White board paint } & CL & 0.70 & 0.06 & 6 & 5733 \\
& OV & 0.59 & 0.04 & 13 & 2718 \\
& POV & 0.60 & 0.08 & 5 & 1447 \\
\hline \multirow{3}{*}{ Aluminium foil } & CL & 0.65 & 0.03 & 7 & 7947 \\
& OV & 0.73 & 0.05 & 6 & 3148 \\
\hline
\end{tabular}

Table 2 provides (a) the mean albedo value, (b) the number of data points, and (c) the standard deviation for the OV, POV, and CL sky conditions of each material. Moreover, it also shows the percentage of standard deviation calculated from the mean albedo and the standard deviation of the albedo value. The reason for such a percentage calculation is that it demonstrates the accuracy of the data collected, i.e., less percentage value means more accuracy and vice versa. The results from the table demonstrate that the percentage deviation of white pebbles was less than that of grass and sand, for almost all sky conditions. Hence, white pebbles have a significant potential to replace grass and sand. Similarly, comparing cement slabs and white tiles with white paint and aluminium foil, the standard deviation of cement slabs was the largest, while that of white tiles was the smallest. However, when looking at the deviation values of aluminium foil, it can be said that if the foil was placed perfectly horizontal, i.e., without any curves or wavy patterns, then it could replace all materials due to its highest albedo value.

In addition to above mentioned analysis, the data points presented in Table 2 were also statistically analysed with the well-known and widely used Chauvenet's Criterion (including Equations (2)-(4)) [40]. This method helped in the task of deciding whether some of the suspect data points are due to experimental error or they represent some physical phenomenon. Needless to say, if the former is the case the data points have to be discarded. Chauvenet's Criterion specifies that a reading may be rejected if the probability of obtaining the particular deviation from the mean is less than $1 / 2 \mathrm{~N}$ and Table 3 is used for this purpose. Table 3 gives the maximum acceptable deviations for various sample sizes.

$$
\begin{gathered}
\text { Arithmetic mean, } X_{m}=\frac{1}{n} \sum_{i=1}^{n} X_{i}, \\
\text { Deviation, } d_{i}=X_{i}-X_{m}, \\
\text { Standard deviation, } \sigma=\left[\frac{1}{n} \sum_{1}^{n}\left(X_{i}-X_{m}\right)^{2}\right]^{\frac{1}{2}},
\end{gathered}
$$


Table 3. Chauvenet's Criterion for rejecting a reading.

\begin{tabular}{cc}
\hline Number of Readings, N & Ratio of Maximum Acceptable Deviation to Standard Deviation, dmax/ $\sigma$ \\
\hline 2 & 1.15 \\
3 & 1.38 \\
4 & 1.54 \\
5 & 1.65 \\
6 & 1.73 \\
7 & 1.8 \\
8 & 1.87 \\
9 & 1.91 \\
10 & 1.96 \\
15 & 2.13 \\
20 & 2.24 \\
25 & 2.33 \\
50 & 2.57 \\
100 & 2.81 \\
300 & 3.14 \\
500 & 3.29 \\
1000 & 3.48 \\
\hline
\end{tabular}

After the analysis of data points presented in Table 2 with Chauvenet's Criterion, it was found that the maximum uncertainty was up to $2.2 \%$. Therefore, it can be interpreted that the data quality is significantly good and uncertainty within the data in quite small.

\section{Discussion}

Grass/Sand: In terms of ageing, the data was recorded for a maximum of 20 days and it was found that the albedo of grass is dependent on the height of its blades, and for sand, it depends on its moisture content. The albedo value of grass and sand stayed fairly constant with respect to solar elevation, however, with an increase in rainfall, a decline in albedo values of both the materials was noted. This is in agreement with Yang [23], who stated that the albedo for soil depends on its moisture and soil colour types, and does not depend on SZA, whereas the albedo for vegetation depends on vegetation characteristics, such as the water layer on grass blades acting as a lens that reflects sun rays in different directions.

White Pebbles: The albedo value of white pebbles was found to be between 0.5 and 0.6 , which unlike conventional materials (grass and sand), did not experience any changes due to rain or sky condition. However, if the pebble bed is close to large plants and/or trees (as it was in the current project) then, it should be cleaned from tree debris every 10 days, otherwise, the albedo value can decrease by $1-2 \%$. Overall, considering all these three materials (grass, sand, and white pebbles) for solar farms, it can be interpreted that white pebbles have good potential to replace conventional materials, with an increase in albedo value of around $2 \%$ and little risk of a declining albedo value due to debris.

Cement slabs/White Tiles: For BAPV applications, the most commonly used materials are cement and tiles. Therefore, in the current research, white tiles and cement slabs were selected. It was concluded that the average albedo value for cement slabs was 0.15 whilst, for white tiles, it was 0.7. According to CPG [41], the average albedo value for new cured grey-cement concrete slabs was around 0.2 and was 0.4 for aged concrete slabs. However, the results of the current investigation depict that the average albedo value of cement slabs for all recorded days was 0.15 . It is likely that such a low albedo value is due to factors, like the composition of concrete, exposure, and ageing. The cement slabs used in the current research were aged five years.

Both cement slabs and white tiles are very hardwearing materials, and hence there was no major impact noticed in terms of wear and tear of the materials. It was, however, noticed that regular maintenance and cleaning was required to maintain the optimum reflectivity. Specifically, for white 
tiles, it was found that within 20 days the reflectivity decreased by almost $5 \%$. Similar results were also noticed by Kultur and Turkeri [42] in Florida, where there was a $24 \%$ decrease within a year using white tiles due to the accumulation of dirt. Similarly, Griggs and Shipp [43] carried out research on tiles for 75 weeks, and they found that initially, the reflectivity of the tiles was 0.8 , which decreased to 0.7 in the first three months and then dropped down to 0.55 at the end of approximately 17 months. Hence, from the current and previous research, it can be concluded that there is always a significant drop in the albedo value of white tiles if they are not cleaned regularly. However, the albedo can be increased from 0.9 to 1 just by washing the surfaces [44]. According to Levinson et al. [45], the decrease in albedo is caused by black carbon and inorganic carbon contaminants, which are deposited over time and should be cleaned off by several cleaning steps to recover the loss of reflectivity. Similar studies on weathered shingles conducted by Akbari et al. [46] suggest that $90 \%$ of un-weathered reflectivity can be recovered by cleaning weathered surfaces. Following these studies, Cheng et al. [47] investigated the natural ageing process of roof tiles under rural and urban sites to find that the three major albedo declining contaminates on soiled samples of about four years of exposure are iron, chromium, and carbon.

In the case of OV sky conditions, i.e., for very low $\mathrm{K}_{\mathrm{T}}$ values, the albedo value decreased to 0.1, whilst during rain, when there was more CL sky conditions (high $\mathrm{K}_{\mathrm{T}}$ values), the albedo value reached up to 0.15 . Hence, it can be interpreted that, in addition to rain, the movement of clouds and cloud cover does play a vital role in albedo values. For white tiles, it was noticed that the albedo value increased as the solar elevation increased. However, there was no change found in albedo values under rainy and non-rainy durations as well. The general albedo value of white tiles under various sky conditions remained between 0.68 and 0.73 . For cement slabs, the albedo values under varying sky conditions (OV, POV, and $\mathrm{CL}$ ) differed by approximately 0.02 , starting from 0.12 and reaching $~ 0.17$.

White Boards: It was found that the albedo value of white painted wooden boards was around 0.62 . The average albedo value of the white board significantly increased with increasing solar elevation from 0.58 to 0.62 . Similarly, the average albedo value of a complete day when it was constantly raining was equivalent to the albedo value under the OV sky condition. Moreover, consideration of the mean albedo values of OV, POV, and CL sky conditions showed that there is a $10 \%$ difference between the albedo values of the OV and CL sky conditions, with $8 \%$ difference between the POV and CL sky conditions.

In terms of the ageing of white board, it was found that within 20 days, the albedo value dropped by $8 \%$ due to dark patches of dirt and dust on the painted board. Moreover, in the last few days, it was noticed that the wooden board started showing signs of fungus due to rain and the moisture from the ground surface (sand). Hence, it can be recommended that if wooden boards are applied for outdoor usage then adding a fungicide is recommended while painting. However, the problem of fungus would not have been caused if the building rooftops were painted with white high reflective paint. Presently, there are numerous high reflective paints available in the market, which could have a higher albedo value than the researched one. It is possible that after applying these new paints, the rooftops behave as a perfect specular foreground. However, in that case, general cleaning would be essential to maintain the high albedo value. According to the manufacturers, the added advantage of these types of new paints are that they are used for cooling rooftops and are available in a wide variety of colours, i.e., there is no specific need to use white coloured ones.

Aluminium Foil: One of the other non-conventional materials for BAPV application was aluminium foil. For the current research purpose, the foil was stapled on the white board. It was found that the albedo value for aluminium foil depends highly on the way of placing the foil, i.e., foil with more curves and bends would have smaller albedo values and vice versa. During the experiment, it was analysed that the outdoor used lifetime of the foil was around 10 days and the maximum albedo value for those days was around 0.76 , which can drop to 0.73 if the foil is not placed perfectly horizontal/straight to the foreground surface. Note: The results of the aluminium foil are solely for kitchen foil, however, if the type of foil is changed, then the behaviour (results) may change. 
Considering different sky conditions, it was found that rainy hours could decrease the albedo value by up to $2 \%$ as compared to albedo values recorded under the OV condition. However, the usual trend of variation in albedo value based on sky condition was noticed as the sky became clear, the albedo value increased, which sometimes reached 0.8 .

\section{Conventional vs. Non-Conventional Materials}

When comparing conventional materials to non-conventional materials, it was concluded that the albedo value of cement slabs was very low as compared to all other materials, while the albedo value of white tiles was higher than white board paint and lower than aluminium foil. The selection of these materials depends highly on the ageing because the aluminium foil has the highest albedo value, but has the lowest lifespan and needs to be changed after almost 10 days (depending on weather conditions, such as high wind). Similarly, the life span of white board paint and white tiles is almost the same, but the drawback of these materials is that they need to be cleaned regularly to maintain their albedo value.

The other emerging material in the Asian market for rooftops along with rooftop PV application is white pebbles. They have a $25 \%$ higher albedo value than cement slabs, which can also be categorised between white tiles and white paint. Usage of white pebbles in a BAPV application have a similar advantage as tiles and paints because they can be used to keep the building cool and release thermal heat. The added advantage of white pebbles is that they block the debris moving to rainwater drainage pipes from building rooftops.

Overall, considering all these foreground materials and their applications in a PV system, it was concluded that the non-conventional materials are much better than the conventional materials. Their albedo values are significantly higher than conventional materials and are less prone to weather. Inaccurate predictions of albedo can lead to significant under-estimations of PV performance, which can lead to sub-optimal design. Furthermore, use of materials of high-reflectance for near the horizon can lead to beneficial gains in energy delivery for solar thermal and PV systems. For example, our calculations have shown that PV panels mounted at 90 degrees facing a grass surface (albedo value of 0.2 ) results in a slope beam irradiation of $435 \mathrm{~W} / \mathrm{m}^{2}$, sky diffuse irradiation of $104 \mathrm{~W} / \mathrm{m}^{2}$, and ground reflected irradiation of $71 \mathrm{~W} / \mathrm{m}^{2}$ (total slope irradiation $=646 \mathrm{~W} / \mathrm{m}^{2}$ ). If the grass horizon is replaced with aluminium foil (albedo value of 0.8 ), this results in ground reflected irradiation increases to $282 \mathrm{~W} / \mathrm{m}^{2}$, leading to a $33 \%$ increase in total slope irradiation $\left(857 \mathrm{~W} / \mathrm{m}^{2}\right)$.

\section{Conclusions}

The summary of four major factors that were studied in this research is provided below.

- Ageing: It can be concluded that the albedo values of grass and sand can vary on the basis of moisture content and height of the grass blades. Similarly, the albedo values of white pebbles, white tiles, and white board paint can decline due to the accumulation of dirt, dust, and plant leaves.

- Solar elevation: The albedo values of grass, sand, and cement slabs remained almost constant at varying solar elevations. Although white pebbles have diffuse ground reflected radiation, the albedo value increased at some solar elevations. White board paint and white tiles also demonstrated an increase in the albedo values at around $40^{\circ}$ to $60^{\circ}$ of solar elevations.

- Rain: During rain spells, almost all materials demonstrated a remarkable decline in their albedo value.

- Cloud cover (sky condition): It was concluded that almost all the materials have higher albedo values under the CL sky condition as compared to OV and POV sky conditions. However, some results demonstrate that the rapid movement of clouds in a small duration of time can cause a significant difference in the albedo values of materials. 
Each material was observed to have individual performance characteristics under these factors. In addition, the decline in the albedo value for some materials can be attributed to the water layer acting as a lens, which can reflect sun rays in different directions. It was found that the non-conventional materials were least prone to weather-related changes and have higher albedo values as compared to the conventional materials. Materials, such as white board, silver foil, and white pebbles, reflect a high percentage of radiation, and therefore it is possible that these materials can substitute or cover typical ground surfaces, such as grass, to increase the amount of radiation received by an inclined PV module to increase their power output.

The results of this study opens doors to further research based on tailoring PV systems more specifically to the climate and geographical location to where they are deployed. The present work is highly relevant and assists both the design and planning of future and existing developments of PV systems, solar space heating systems, and solar water heating systems to increase their relative power output; thus, helping to lower carbon emissions and secure energy for future generations.

Within this research, some limitations were identified that restricted a full in-depth analysis to take place. Firstly, the impact of ground albedo was only tested for a short duration of two weeks. Testing a material for two weeks only accounts for $5 \%$ of the year and therefore does not provide a true indication of how albedo values vary and possibly deteriorate over time. It is therefore recommended for further studies to increase the test period to account for all seasonal weather changes. In addition, due to limited resources and equipment, only one material could be tested at one time between April and September. This meant that each material was tested at a different period within the year and therefore was subjected to different atmospheric conditions where the impact of snow and ice is unaccounted for. For further research, it would be recommended to test the materials simultaneously to ensure each material is exposed to the same levels of radiation and atmospheric conditions, including snow cover.

Further work is also required to understand the ageing process of different materials and the level of maintenance that it entails, e.g., how often aluminium foil needs to be replaced depending on its quality, and by controlling the level of moisture in sand and analysing its impact on its albedo.

Author Contributions: The individual contributions of authors are as follows: Conceptualization, M.G. and Y.K.; methodology, T.M.; software, T.M. and S.I.; validation, M.G., T.M. and S.I.; formal analysis, Y.K.; investigation, M.G. and Y.K.; resources, M.G.; data curation, Y.K.; writing—original draft preparation, Y.K.; writing-review and editing, M.G. and T.M.; visualization, M.G. and Y.K.; supervision, M.G.; project administration, M.G.; funding acquisition, M.G.

Funding: This research received no external funding.

Acknowledgments: In this section you can acknowledge any support given which is not covered by the author contribution or funding sections. This may include administrative and technical support, or donations in kind (e.g., materials used for experiments).

Conflicts of Interest: The authors declare no conflict of interest.

\section{References}

1. Thevenard, D.; Driesse, A.; Pelland, S.; Turcotte, D.; Poissant, Y. Uncertainty in Long-Term Photovoltaic Yield Predictions; Canmet Energy Report; Natural Resources Canada: Ottawa, ON, Canada, 2010.

2. Polescu, M.; Pailescu, E.; Gravila, P.; Baddescu, V. Solar Radiation Measurements. In Weather Modeling and Forecasting of PV Systems Operation; Springer: London, UK, 2013; pp. 17-42.

3. Kotak, Y.; Gul, M.S.; Muneer, T.; Ivanova, S.M. Investigating the Impact of Ground Albedo on the Performance of PV Systems; Chartered Institution of Building Services Engineers (CIBSE): London, UK, 2015.

4. Hay, J.E.; McKay, D.C. Estimating Solar Irradiance on Inclined Surfaces: A Review and Assessment of Methodologies. Int. J. Sol. Energy 2007, 3, 203-240. [CrossRef]

5. Muneer, T. Solar Radiation Modeling for the United Kingdom. Ph.D. Thesis, Council of National Academic Award (CNAA), London, UK, 1987.

6. Psiloglou, B.E.; Balaras, C.A.; Santamouris, M.; Asimakopoulos, D.N. Evaluation of Different Radiation and Albedo Models for the Prediction of Solar Radiation Incident on Tilted Surfaces, for Four European Locations. ASME J. Sol. Energy Eng. 1996, 118, 183-189. [CrossRef] 
7. Liu, B.Y.; Jordan, R.C. The long-term average performance of flat-plate solar-energy collectors: With design data for the U.S., its outlying possessions and Canada. Sol. Energy 1963, 7, 53-74. [CrossRef]

8. Ineichen, P.; Guisan, O.; Perez, R. Ground-reflected radiation and albedo. Sol. Energy 1990, 44, $207-214$. [CrossRef]

9. CIBSE. Environmental Design: CIBSE Guide A, 7th ed.; The Chartered Institution of Building Services Engineers: London, UK, 2006.

10. Kimball, B.A.; Jackson, R.D.; Barfield, B.J.; Gerber, J.F. Modification of the aerial environment of crops. Soil Heat Flux ASAE Monogr. 1979, 2, 211-229.

11. Oke, T.R. Boundary Layer Climates, 2nd ed.; Taylor \& Francis Group Ltd.: Oxford, UK, 1987.

12. Campbell, G.S.; Norman, J.M. An Introduction to Environmental Biophysics, 2nd ed.; Springer: New York, NY, USA, 1988.

13. Muneer, T.; Gueyard, C.; Kambezidis, H. Solar Radiation and Daylight Models; Taylor \& Francis: Oxford, UK, 2004; pp. 303-316.

14. SOLMET. Hourly Solar Radiation-Surface Meteorological Observations. Available online: ftp://ftp. ncdc.noaa.gov/pub/data/metadata/documents/C00045_TD-9734-TMY-manual-1981.pdf (accessed on 23 October 2018).

15. Iqbal, M. An Introduction to Solar Radiation, 1st ed.; Academic Press: New York, NY, USA, 1983.

16. Ineichen, P.; Perez, R.; Seals, R. The importance of correct albedo determination for adequately modeling energy received by tilted surfaces. Sol. Energy 1987, 39, 301-305. [CrossRef]

17. Photovoltaic-software.com, PVGis (2013). Available online: http://photovoltaic-software.com/pvgis.php (accessed on 28 March 2018).

18. Munn, R.E.; Truhlar, E.J. The energy budget approach to heat transfer at the surface of the earth. Trans. Eng. Inst. Can. 1963, 6, 1-20.

19. Impens, I.; Lemeur, R. The radiation balance of several field crops. Theor. Appl. Clim. 1969, 17, $261-268$. [CrossRef]

20. Bolsenga, S.J. Preliminary observations on the daily variation of ice albedo. J. Glaciol. 1977, 18, 517-521. [CrossRef]

21. Bray, J.R.; Sanger, J.E.; Archer, A.L. The visible albedo of surfaces in central Minnesota. Ecology 1996, 47, 524-531. [CrossRef]

22. Volz, F. The dependence of albedo on solar elevation. Pure Appl. Geophys. 1965, 60, 197-200. [CrossRef]

23. Yang, F. Parameterizing the Dependence of Surface Albedo on Solar Zenith Angle Using Atmospheric Radiation Measurement Program Observations. In Proceedings of the Sixteenth ARM science team meeting proceedings, Albuquerque, NM, USA, 27-31 March 2006.

24. Idso, S.B. The Dependence of Bare Soil Albedo on Soil Water Content. J. Appl. Meteorol. 1974, 14, $103-119$. [CrossRef]

25. Idso, S.B.; Reginato, R.J. Assessing soil-water status via albedo measurement. In Hydrology and Water Resources in Arizona and the Southwest; Arizona-Nevada Academy of Science: Flagstaff, AZ, USA, 1974.

26. Matthias, A.D.; Fimbres, A.; Sano, E.E.; Post, D.F.; Accioly, L.; Batchily, A.K.; Ferreira, L.G. Surface roughness effects on soil albedo. Soil Sci. Soc. Am. J. 2000, 64, 1035-1041. [CrossRef]

27. Ramírez, A.Z.; Muñoz, C.B. Albedo Effect and Energy Efficiency of Cities. In Sustainable Development-Energy, Engineering and Technologies-Manufacturing and Environment; 2012; Available online: https://www.intechopen.com/books/sustainable-development-energy-engineering-andtechnologies-manufacturing-and-environment/albedo-effect-and-energy-efficiency-of-cities (accessed on 28 October 2018). [CrossRef]

28. NASA Earth Observatory. Global Albedo (2002). Available online: https://earthobservatory.nasa.gov/ images/2599/global-albedo (accessed on 12 October 2018).

29. Frotini, F.; Bonomo, P.; Chatzipanagi, A.; Verberne, G.; Donker, M.; Folkerts, W. BIPV Product Overview for Solar Facades and Roofs. Available online: https:/ / www.academia.edu/17603297/SEAC_SUPSI_report_ 2015_BIPV_product_overview_for_solar_facades_and_roofs (accessed on 28 October 2018).

30. ASTM. ASTM E1918-06 Standard Test Method for Measuring Solar Reflectance of Horizontal and Low-Sloped Surfaces in the Field. Available online: https:/ / www.astm.org/DATABASE.CART/HISTORICAL/E191806R15.htm (accessed on 28 October 2018). 
31. Li, H.; Harvey, J.; Kendall, A. Field measurement of albedo for different land cover materials and effects on thermal performance. Build. Environ. 2013, 59, 536-546. [CrossRef]

32. Howell, J.R.; Menguc, M.P.; Siegel, R. Thermal Radiation Heat Transfer, 5th ed.; Chemical Rubber Company (CRC) Press: Boca Raton, FL, USA, 2011.

33. Muneer, T. Solar Radiation Daylight Models for the Energy Efficient Design of Buildings, 2nd ed.; Elsevier Butterworth-Heinemann: Oxford, UK, 2004.

34. Kheradmand, S.; Nematollahi, O.; Ayoob, A.R. Clearness index predicting using an integrated artificial neural network (ANN) approach. Renew. Sustain. Energy Rev. 2016, 58, 1357-1365. [CrossRef]

35. Murmson, S. What Is Solar Altitude? Available online: http:/ / classroom.synonym.com/solar-altitude-23364. html (accessed on 5 November 2016).

36. Ferncase, R. Basic Lighting Worktext for Film and Videos, 1st ed.; Focal Press: Abingdon, UK, 1992.

37. Angstrom, A. The albedo of various surfaces of ground. Geogr. Ann. 1925, 7, 323-342.

38. Weisstein, E.W. Snell's Law. Available online: http://scienceworld.wolfram.com/physics/SnellsLaw. html2007 (accessed on 20 January 2017).

39. Bowers, S.A.; Hanks, R.J. Reflection of radiant energy from soils. Soil Sci. 1965, 100, 130-138. [CrossRef]

40. Bayless, D. Statistical Rejection of “Bad” Data-Chauvenet's Criterion 2005. Available online: https:// chetaero.files.wordpress.com/2016/11/chauvenet.pdf (accessed on 13 October 2018).

41. Concrete Promotional Group (CPG). Light Reflectivity-Sustainability 2016. Available online: http:/ / www. concretepromotion.com/education_11.html (accessed on 17 September 2016).

42. Kültür, S.; Türkeri, N. Assessment of long term solar reflectance performance of roof coverings measured in laboratory and in field. Build. Environ. 2012, 48, 164-172. [CrossRef]

43. Griggs, E.I.; Shipp, P.H. The impact of surface reflectance on the thermal performance of roofs: An experimental study. ASHRAE Trans. 1988, 94, 2.

44. Bretz, S.E.; Akbari, H. Long-term performance of high-albedo roof coatings. Energy Build. 1997, 25, $159-167$. [CrossRef]

45. Levinson, R.; Berdahl, P.; Berhe, A.A.; Akbari, H. Effects of soiling and cleaning on the reflectance and solar heat gain of a light-colored roofing membrane. Atmos. Environ. 2005, 39, 7807-7824. [CrossRef]

46. Akbari, H.; Berhe, A.A.; Levinson, R.; Graveline, S.; Foley, K.; Delgado, A.H.; Paroli, R.M. Aging and weathering of cool roofing membranes. In Proceedings of the First international conference and Lawrence Berkeley National Laboratory (LBNL 58055), Berkeley, CA, USA, 17 May 2005.

47. Cheng, M.D.; Miller, W.; New, J.; Berdahl, P. Understanding the long-term effects of environmental exposure on roof reflectance in California. Constr. Build. Mater. 2012, 26, 516-526. [CrossRef] 